\title{
Generality of US preexposure effects: Transfer from food to shock or shock to food with and without the same response requirements
}

\author{
TAMIR CASPY \\ Bar-Ilan University, Ramat Gan, Israel \\ and \\ R. E. LUBOW \\ Tel Aviv University, Ramat Aviv, Israel
}

\begin{abstract}
A series of four experiments, employing mice, investigated the generality of the learned helplessness phenomenon. The first two experiments used preexposure to aversive stimuli (shock), while the other two used preexposure to appetitive stimuli (food). In all of the studies, subjects were preexposed to contingent, noncontingent, or no stimuli (except for Experiment 2) in a Skinner box. During the test, animals preexposed to shock were tested with food, and those preexposed to food were tested with shock. The test was conducted in a similar situation, a Skinner box (Experiments 1,3), or a different situation-a runway (Experiments 2, 4). Performance decrements were evident when subjects that were preexposed to a noncontingent stimulus were compared with subjects preexposed to contingent stimuli. The differences between the contingent and the noncontingent groups were significant, as were the differences between the contingent and the nonpreexposed groups (except for Experiment 1). The effects cut across the different types of stimuli, situations, and response requirements of the preexposure and test phases.
\end{abstract}

It has been repeatedly shown that subjects exhibit a marked decrement in instrumental behavior following preexposure to a US that is independent of the subject's response (see Maier \& Seligman, 1976, for a review). In early demonstrations, Overmier and Seligman (1967) and Seligman and Maier (1967) found that dogs preexposed to inescapable shock failed to acquire a subsequent shuttle escape response, whereas dogs that were preexposed to escapable shock efficiently learned to escape the shock. This interference phenomenon is often referred to as learned helplessness ( $\mathrm{LH})$.

According to the learned helplessness hypothesis (Maier \& Jackson, 1979; Maier \& Seligman, 1976; Seligman, 1975), organisms exposed to situations in which responses and outcomes are independent of each other learn that these events are uncontrollable and acquire the general expectation of continued response-outcome independence. This results in reduced motivation to control reinforcements in new situations and reduced ability to form new associa-

This paper is part of an MA thesis submitted to Bar-Ilan University in partial fulfillment of the requirements for the MA degree by the first author under the direction of the second author. Correspondence should be directed to R. E. Lubow, Department of Psychology, Tel Aviv University, Ramat Aviv, Israel. tions. One of the primary characteristics of this interference phenomenon is the very broad generalization from conditions of induction to conditions of test. A number of studies have investigated various aspects of this generalization. For instance, it has been found that presentation of an uncontrollable shock affects subsequent water-escape performance (Braud, Wepmann, $\&$ Russo, 1969). Another aspect of the generalization effect is the occurrence of learned helplessness across different apparatus in the preexposure and tests situations (e.g., Seligman, Rosellini, \& Kozak, 1975). In addition, Goodkin (1976) showed a decremental effect using different response requirements in preexposure and test, whereas Altenor, Kay, and Richter (1977) demonstrated that the learned helplessness effect can be produced by either preexposure to water and testing with shock or preexposure to shock and testing in water, as well as in the usual manner, in which preexposure stimuli and test stimuli are the same.

Compared with the large number of $\mathrm{LH}$ studies employing aversive stimuli, relatively few experiments have used appetitive stimuli. In these studies, subsequent retardation of learning has been observed when reward was given "free" during the preexposure phase, that is, independently of the organism's responses (Caspy, Frommer, Weiner, \& Lubow, 
1979; Engberg, Hansen, Welker, \& Thomas, 1973; Goodkin, 1976; Mullins \& Winefield, 1977; Welker, 1976; White \& Katzev, 1977). Within the appetitive learned helplessness framework, only two studies have been concerned with generalization phenomenon. Caspy et al. (1979) demonstrated that preexposure to uncontrollable, as opposed to controllable, food produced a subsequent decrement in a swimming task. Goodkin (1976) showed that preexposure to uncontrollable food, as compared with controllable food, interfered with the acquisition of a nose-press-to-escape-shock response.

The almost ubiquitous generalization of interference following exposure to uncontrollable appetitive or aversive events would seem to favor the learned helplessness hypothesis as compared with the positions that appeal to the transfer of inactivity from preexposure to test (e.g., Anisman, de Cantanzaro, \& Remington, 1978; Glazer \& Weiss, 1976a, 1976b). However, the domain of generalization has not been completely explored. It is the purpose of the present set of experiments to provide some of the data to help complete the description of these generalization effects. To this end, four experiments were conducted. In Experiment 1, subjects were exposed to escapable, inescapable, or no shock and then were tested with food. Response requirements in the two phases were constant (i.e., barpress to terminate shock and barpress to receive food). Experiment 2 was the same as Experiment 1, except that the noshock group was omitted, and the response requirements were changed from preexposure to test, barpress, and running, respectively. In Experiment 3, subjects were exposed to contingent, noncontingent, and no food, and were tested on an escape from shock task. Barpressing was required in both phases. Experiment 4 used the same design; however, response requirements were changed so that during preexposure, as in Experiment 2, a barpress was required, while during test, running plus barpressing was required. The main purpose of these four experiments was to demonstrate and measure, within one study, the generalization effect across different situations, stimuli, and response requirements during preexposure and test phases. An additional purpose of these experiments was to demonstrate generalization of $\mathrm{LH}$ in the mouse. A limited number of LH studies have used mice as subjects, and some have, indeed, demonstrated generalization. Braud et al. (1969) showed that the interference effect generalized across different aversive events (from shock to water). Caspy et al. (1979) found similar results and also found that there is a transfer of interference when mice are preexposed to a response noncontingent appetitive event (food) and are tested in an aversive situation (water escape). The present study, then, extends the study of generalization of
LH in mice by examining transfer from food to shock and from shock to food.

Finally, a subsidiary purpose was to evaluate differences in behavior due to preexposure of uncontrollable short-duration $(2 \mathrm{sec})$ and long-duration $(6 \mathrm{sec})$ shock. According to the inactivity hypothesis, uncontrollable short-duration shock does not produce an activity decrement (e.g., Anisman et al., 1978) and therefore should not result in a subsequent interference effect. In Experiments 1 and 2, duration of uncontrollable shock during preexposure was included as one of the variables.

\section{EXPERIMENT 1}

The majority of studies investigating the learned helplessness phenomenon have used preexposure to inescapable shock followed by a test that also employs shock. The purpose of the following experiment was to study the generality of preexposure to an inescapable aversive stimulus (shock) on the acquisition of an appetitive instrumental response. In addition, the effects of long vs. short duration of escapable/inescapable shock on subsequent performance were compared.

\section{Method}

Subject and Design. Forty-eight male BALB-c mice, obtained from the Bar-Ilan University vivarium and 60-63 days of age at the start of the experiment, served as subjects. Mice were housed in groups of five. Experimental training and testing were carried out during the light portion of a 12-h light/dark cycle.

The experimental design included the shock treatment: escapable shock (ES), inescapable shock (IES), or no shock (NS) as one factor, and shock duration ( $2 \mathrm{vs} .6 \mathrm{sec}$ ) as the second factor. Eight mice were assigned randomly to each of the six groups. There were eight replications with one subject from each of the six experimental groups.

Apparatus. The preexposure phase of the experiment was conducted in six identical $10 \times 16 \times 18 \mathrm{~cm}$ transparent, red Plexiglas chambers, with transparent, colorless tops. The chamber floor was composed of stainless steel bars, $3.3 \mathrm{~mm}$ in diameter and spaced $7 \mathrm{~mm}$ from edge to edge. Constant shock of .5-mA dc (half-wave rectified) from a $50-\mathrm{Hz} 500-\mathrm{V}$ ac source was delivered to the grid floor. A bar (Cherry, E-23), protruding $2.6 \mathrm{~cm}$ from the center of one wall, was located $2.3 \mathrm{~cm}$ from the grid floor and required a $10-\mathrm{g}$ force to activate. All experimental conditions were controlled by solid state programming equipment.

The test phase was conducted in two identical $9.6 \times 9.6 \times$ $13.5 \mathrm{~cm}$ chambers. The walls of the apparatus were made of red Plexiglas, and the top was covered by clear Plexiglas. The apparatus floor was composed of stainless steel bars, $1.6 \mathrm{~mm}$ in diameter, and was spaced $5 \mathrm{~mm}$ from edge to edge. A bar (Cherry, E-23) protruded $1.85 \mathrm{~cm}$ from the wall and was located $3 \mathrm{~cm}$ from the grid floor. The bar required a $10-\mathrm{g}$ force to activate. The grids were connected to a dc constant current shock source, as described above.

Procedure. Three days prior to, and for the duration of, the experiment, mice were kept on a 23 -h food-deprivation schedule. During the first 4 days, the subjects had free access to $45-\mathrm{mg}$ Noyes food pellets for $.5 \mathrm{~h}$ in the test chambers. This was followed by $.5 \mathrm{~h}$ access to food in the home cage. For the remainder of the experiment, each animal had free access to food for $1 \mathrm{~h}$ in his home cage immediately following training or testing. 
In the preexposure phase, subjects-in squads of six, two from each group (ES, IES, NS) - were run simultaneously in the chambers. Shocked animals received $90.5-\mathrm{mA}$ shocks. Half of these subjects received shock for a nominal 2 -sec duration, and half received it for a nominal $6-\mathrm{sec}$ duration. The average ISI, measured from shock offset to shock onset, was $20 \mathrm{sec}$, with a range between 12 and $30 \mathrm{sec}$. Mice from the ES group could terminate the shock by a single barpress. Each subject in Group IES was yoked to an animal in Group ES, so that each pair received identical shock intensity and duration (i.e., shock termination for subjects in the IES group occurred when the ES subject made the barpress). Subjects in the NS group were placed in the Plexiglas chambers for the same amount of time as were the ES and IES groups but were not exposed to shock. The number of trials on which a barpress response was made was recorded for all subjects.

Twenty-four hours after the preexposure phase, each of the subjects was put into the test compartment. A 45-mg Noyes food pellet was delivered for each barpress. Twenty-two hours after home cage feeding, the second session was initiated. The same procedure was repeated on the 3rd day. Running order during the test was randomized within each squad of six mice. The number of barpresses for every $.5 \mathrm{~h}$ of each of the three $1 \mathrm{~h}$ sessions was recorded.

\section{Results and Discussion}

Preexposure phase. Figure 1 represents the mean number of barpresses for each of the six groups over the three blocks of 30 trials. A groups (3) $\times$ shock duration (2) $\times$ blocks (3) three-way ANOVA, with one factor repeated, indicated a signficant effect of groups $[F(2,42)=180.39, p<.001]$ and blocks $[\mathrm{F}(2,84)=2.94, \mathrm{p}<.01]$ and a groups $\times$ blocks interaction $[F(4,84)=72.22, p<.001]$. The groups $x$ shock duration interaction was also found to be significant $[F(2,42)=11.39, p<.001]$. Subsequent Newman-Keuls multiple comparisons $(\alpha \cdot=.05)$ for the three groups at each level of block were carried out. These comparisons revealed that, for the IES subjects, responding declined significantly from block to block when 6-sec shocks were delivered and only from the second to the third block when 2 -sec

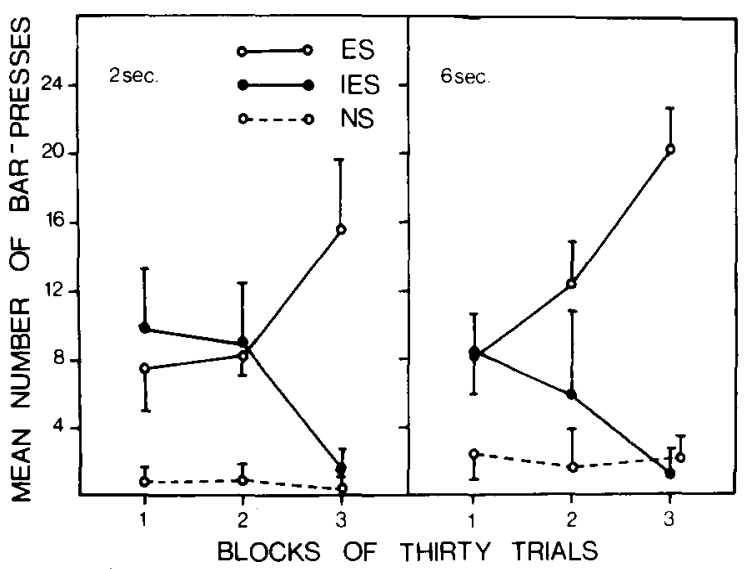

Figure 1. Mean ( \pm SD) number of barpresses during preexposure over blocks of $\mathbf{3 0}$ trials as a function of shock treatment (escapable shock:ES; inescapable shock: IES; and no shock: NS), and shock duration ( 2 vs. $6 \mathrm{sec}$ ).

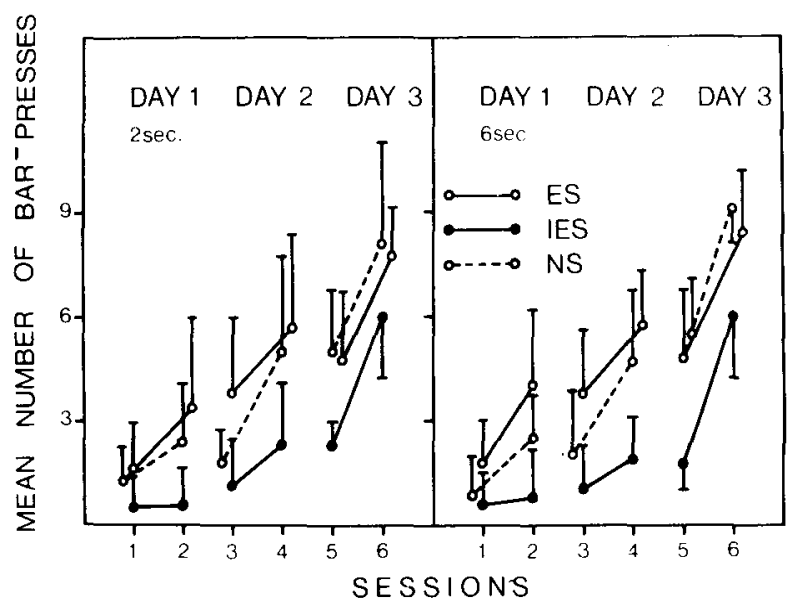

Figure 2. Mean ( \pm SD) number of barpresses for food during test over six blocks of $.5 \mathrm{~h}$ each as a function of shock treatment (escapable shock: ES; inescapable shock: IES; and no shock: NS), and shock duration ( 2 vs. 6 sec).

shocks were used. ES subjects' responding increased significantly from block to block when 6-sec shocks were administered and only from the second to the third block when 2-sec shocks were used. In addition, with 2-sec shock, there were significant differences between the IES and NS groups for the two first blocks. With 6-sec shock, reliable differences between IES and NS groups were obtained only on the first blocks. ES and IES groups differed reliably on the last block when 2-sec shocks were delivered and on the two last blocks when the 6-sec shocks were delivered.

The general picture, then, is that the ES group learned to control shock offset, as shown by the increasing number of responses across blocks. The IES group, although initially responding at a level equal to the ES group, dropped to the same low level exhibited by the no shock group.

Test phase. Mean number of bar presses for food for each of the six groups during test across the two .5-h blocks of each daily session is shown in Figure 2 . A groups (3) $\times$ shock duration (2) $\times$ blocks (6) threeway ANOVA, with one factor repeated, yielded a significant groups effect $[F(2,42)=46.15, p<.001]$ and blocks effect $[F(5,210)=83.70, p<.001]$. In addition, the groups $\times$ blocks interaction was also significant $[\mathrm{F}(10,210)=2.38, \mathrm{p}<.01]$. All other effects were not significant $(F<1)$.

Newman-Keuls multiple comparisons among the three groups at each level of the six blocks revealed significant differences between the ES and the IES groups for each block, except for the first block for both 2- and 6-sec shock duration. The IES and NS groups differed reliably from the fourth block through the sixth block. In addition, whereas barpress performance of the ES and NS groups increased significantly from day to day for all 3 days, for the IES group this increment was evident only when the last 
2 days were compared. As noted above, there were no reliable differences in number of first, second, or third block barpresses between the IES and NS subjects exposed to both shock durations.

The results described above are consistent with other studies that investigated the learned helplessness generality phenomenon (e.g., Caspy et al., 1979; Goodkin, 1976; Rosellini, 1978). Preexposure to an inescapable aversive stimulus (shock) interferes with later performance using an appetitive stimulus (food).

The pattern of responding for food during the test phase was similar for the two different shock durations, 2 and $6 \mathrm{sec}$. Subjects who were exposed to escapable shock or to no shock performed better than those subjects who were exposed to inescapable shock of both durations. Shock duration, then, had no effect on later performance.

It might be argued that the differences between the groups were a product of simple transfer. This possibility arises because of the use of the same response (FR-1 barpress) during both preexposure and test for the ES group. However, this was probably not the case. The groups that were preexposed to escapable, inescapable, and no shock all showed similar test performance on the first block. The differences among the groups emerged only after Block 1. A simple transfer explanation of the improved test performance for the ES group would seem to require that these effects appear at the very beginning of the test phase. In regard to the differences between the inescapable shock and the no shock groups, these effects, of course, are unrelated to the response requirements of the escapable shock group, and therefore must be interpreted as the result of lack of contingency for the IES group.

\section{EXPERIMENT 2}

It is evident from the results of Experiment 1 that preexposure to inescapable shock retards later barpress performance in an appetitive procedure. However, the same response, barpress, was used in the preexposure phase for shock escape and in the test phase for food acquisition. Experiment 2 was designed to study the effect of escapable/inescapable shock preexposure on a subsequent test that employs an appetitive procedure with a response different from that used in preexposure. In this experiment, a barpress to escape shock continued to be used in the preexposure phase, but a running response in a straight alley was used in the test phase. This procedure also circumvents the problem of direct transfer that was raised in the discussion section of Experiment 1 . In addition to using running speed as a measure of learning during the acquisition session, the number of retraces was counted (Amsel, Rashotte, \& Mackinon, 1966). This was done in order to obtain a measure of activity that might influence the speed measure but would have an opposite theoretical meaning. Thus, while decreased running speed might reflect inactivity, retraces would result in such a decrease but would suggest an increase in activity. This measure, then, might provide some information concerning the inactivity explanations of the effects of uncontrollable shock (Chen \& Amsel, 1977).

\section{Method}

Subjects and Design. Thirty-two male BALB-c mice, 61-65 days of age at the start of the experiment, served as subjects. All subjects' specifications were the same as described in the previous experiment. A $2 \times 2$ factorial design was employed: shock treatment (escapable vs. inescapable) and shock duration ( 2 vs. $6 \mathrm{sec}$ ). Subjects were run in squads of four. The experiment consisted of eight replications with eight subjects in each group.

Apparatus. For the preexposure phase, four chambers, as described in Experiment 1, were used. The test phase was conducted in a straight alley that consisted of a startbox (SB), a runway, and a goalbox (GB) at the end of the runway. Each of the two compartments, $\mathrm{SB}$ and GB, measured $9.6 \times 9.6 \times 13.5 \mathrm{~cm}$. The runway was $39.6 \mathrm{~cm}$ in length. The walls of the apparatus were made of red Plexiglas, and the top was clear Plexiglas. The inside partitions separating SB and GB from the runway were opaque Plexiglas. The partition forming the entrance to GB contained a 5.0 -cm-diam aperture, the lowest point of which was $2.8 \mathrm{~cm}$ above the grid floor. The floor was made of stainless steel bars, $1.6 \mathrm{~mm}$ in diameter and spaced $5 \mathrm{~mm}$ apart.

Procedure. All animals were placed on a 23-h food-deprivation schedule for 3 days, as in Experiment 1. In addition, for these 3 days, the mice were allowed to explore the runway for $5 \mathrm{~min}$ before being fed. The deprivation schedule was continued throughout the experiment.

In the preexposure phase, subjects-in squads of four, one from each group-were run simultaneously in the Plexiglas chambers. Shock animals received $90.5-\mathrm{mA}$ shocks. Half of these subjects received shock for a nominal 2 -sec duration, and half received it for a nominal 6-sec duration. Mice from the ES group could terminate the shock by a single barpress. Each subject in Group IES was yoked to an animal in Group ES. The procedure was identical to that employed in Experiment 1.

Twenty-four hours after shock administration, the animals were placed individually in the startbox. The subject remained in the box for $1 \mathrm{sec}$, after which the startbox door was raised. Simultaneously with raising the door, a timer was started. The timer was stopped by the experimenter when the mouse passed, with all four legs, through the hole in the second partition, the entrance to the goalbox. Mice remained in the goalbox until food, a $45-\mathrm{mg}$ Noyes pellet, was consumed. The ITI between trials ranged from 1 to 2 min. Each animal received 18 trials. Running order was randomized among subjects from the same squad.

Retrace data, defined as 180 -deg turns away from the goalbox, were also recorded. A maximum of one retrace response for each trial was counted.

\section{Results and Discussion}

Preexposure phase. The course of responding over the 30 trials is very similar to that depicted in Figure 1 for the ES and IES groups of Experiment 1. The mean numbers of barpresses for each of the four groups were subjected to a groups $(2) \times$ shock duration (2) $\times$ blocks (3) three-way ANOVA, with one factor repeated. The analysis indicated significant differences for groups $[F(1,20)=62.59, p<.001]$ and blocks $[F(2,56)=8.90, p<.001]$, and the groups $x$ blocks $[F(2,56)=55.47, p<.001]$ and groups $x$ 
shock durations interactions $[F(1,20)=17.59$, $p<$ $.001]$ were also significant. Subsequent Newman-Keuls multiple comparisons revealed that responding of IES subjects declined significantly from block to block when 6-sec shocks were delivered and from the second to the third block when 2-sec shocks were used. For the ES subjects, however, responding increased significantly from block to block when 6-sec shocks were administered and only from the second to the third block when 2-sec shocks were used. A comparison between the two groups at each level of blocks revealed that the ES subjects performed better during the last two blocks when 6-sec shock duration was used and during the last block when 2-sec shock duration was used.

Test phase. Mean latency (time to travel from startbox to goalbox) for the four groups over three blocks of six trials is shown in Figure 3. A groups (2) $x$ shock duration (2) $x$ blocks (3) three-way ANOVA, with one factor repeated, revealed a significant effect of groups $[\mathrm{F}(1,20)=235.46, \mathrm{p}<.001]$ and blocks $[F(2,56)=440.60, p<.001]$. The groups $\times$ blocks and the groups $\times$ shock duration $\times$ blocks interactions were also found to be significant $[F(2,56)=$ $13.42, \mathrm{p}<.001 ; \mathrm{F}(2,56)=10.20, \mathrm{p}<.001$, respectively]. The latter interaction reflects, in part, the fact that the IES-6-sec group responded more slowly on blocks 2 and 3 than did the IES-2-sec group.

Newman-Keuls multiple comparisons for the two groups at each level of blocks and shock durations revealed that IES subjects were slower than the ES subjects on all blocks. Subjects' time decreased from block to block, except for the IES subjects who were preexposed to 6-sec shock duration. For this group, the difference between the first and the second block was not significant.

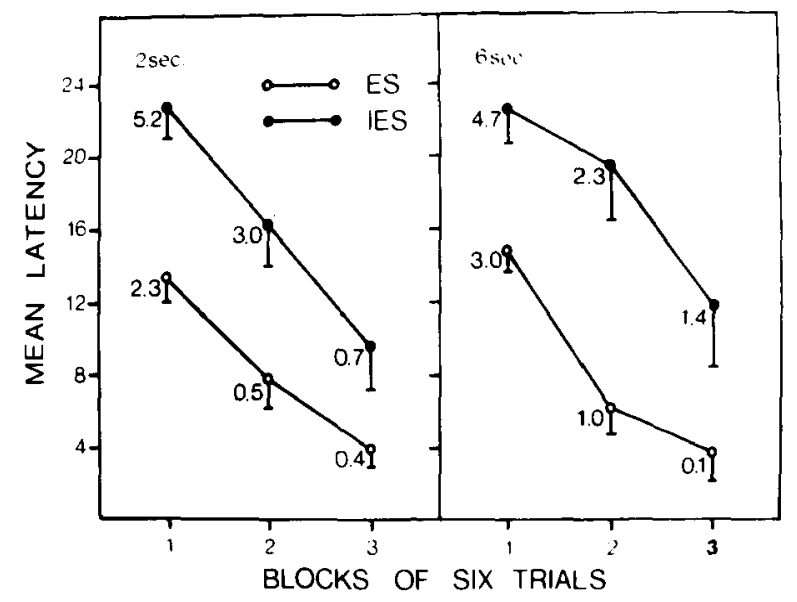

Figure 3. Mean ( \pm SD) latency to goalbox entry during test over blocks of six trials as a function of shock treatment (escapable shock: ES; inescapable shock: IES) and shock duration (2 vs. $6 \mathrm{sec}$ ). Numbers represent the mean number of retrace responses.
Figure 3 also presents the mean number of retrace responses for the four groups over blocks of six trials each. (These values are indicated next to the latency information.) A groups (2) $\times$ shock duration $(2) \times$ blocks, (3) three-way ANOVA, with one factor repeated, yielded a significant difference between groups $[\mathrm{F}(1,28=40.32, \mathrm{p}<.001]$ and among blocks $[\mathrm{F}(2,56)=76.85, \mathrm{p}<.001]$. The groups $x$ blocks interaction was also significant $[F(2,56)=$ $4.44, \mathrm{p}<.01]$.

Newman-Keuls multiple comparisons between the ES and the IES groups at each level of blocks and shock duration revealed that the IES group made more retrace responses than did the ES group on all blocks, except for the last block, when 2-sec shocks were used. Number of retrace responses for both groups decreased from block to block, except for the ES-2-sec shock group, in which the difference between the second and the last block was not significant.

It is clear from the data of Experiment 2 that there is an interference effect on a subsequent task following preexposure to inescapable shock. This effect occurred in spite of the fact that different stimuli were used during preexposure and test (shock and food, respectively) and that different responses were required during preexposure and test (barpress and running, respectively). As in Experiment 1, the interference effect was demonstrated for subjects preexposed to either 2 or $6 \mathrm{sec}$ of uncontrollable shock.

The retrace data are similar to those reported by Chen and Amsel (1977). Subjects exposed to inescapable shock (whether of short or long duration) made significantly more retrace responses than did subjects who were exposed to escapable shock. These data are inconsistent with the Glazer and Weiss (1976a, 1976b) inactivity interpretation. If performance deficits in the test are due to the transfer of inactivity that was learned during preexposure, then the differences in retraces should be in the direction opposite to that reported here. Retraces, as operationally defined above, would seem to reflect high activity. However, it should be noted that the retrace and latency data are probably dependent on each other. Thus, subjects of the IES group who had longer latencies also had more opportunity to retrace-or, the opposite, subjects who retraced would tend to have elevated latencies.

\section{EXPERIMENT 3}

According to Seligman and Maier (1976), the absence of a response-outcome contingency can be learned in both aversive and appetitive conditions. Indeed, a number of studies have shown a retardation effect following exposure to noncontingent appetitive stimuli (Caspy et al., 1979; Goodkin, 1976; Welker, 1976; Wheatley, Welker, \& Miles, 
1977; White \& Katzev, 1977). The purpose of the following experiment was to study the effect of preexposure to a noncontingent appetitive event on the acquisition of an escape-from-shock response. Whereas most of the studies that investigated the effect of preexposure to an appetitive noncontingent stimulus used different preexposure and test response requirements with similar stimuli (Caspy et al., 1979; Engberg et al., 1973; Welker, 1976; Wheatley et al., 1977; White \& Katzev, 1977), this experiment used similar response requirements: barpressing to obtain food during preexposure and barpressing to escape shock during test while varying the stimulus conditions-food during preexposure and shock during test.

\section{Method \\ Subjects and Design. Forty-eight male BALB-c mice, 61-65 days of age at the start of the experiment, were used. All other speci- fications were identical to those described previously. In the pre- exposure phase, there were three groups: contingent reinforce- ment, noncontingent reinforcement, and no reinforcement. The subjects from each group were divided into two additional groups during test-2- and 6-sec shock duration. There were eight rep- lications of the $3 \times 2$ factorial design. Each replication consisted} of six mice.

Apparatus and Procedure. For 3 days prior to the experimental manipulations, mice were put on a food-deprivation schedule similar to that described earlier. On the following 3 days, mice were placed individually in one of the two preexposure compartments, described in Experiment 2, for a 1-h daily session. One group, response contingent reinforcement (CR), was exposed to a continuous reinforcement schedule in which each barpress was followed by delivery of a $45-\mathrm{mg}$ Noyes food pellet. The second group, response noncontingent reinforcement (NCR), was yoked to the CR group such that each food reinforcement that the CR subject received was simultaneously delivered to its NCR partner, irrespective of its responding. The subjects of the third group, no preexposure to food (NP), also were placed in the apparatus for $1 \mathrm{~h}$. All subjects received ad-lib food and water for $1 \mathrm{~h}$ after the termination of each daily session.

Twenty-four hours after the preexposure phase, the test was initiated. The test was conducted in three of the chambers used for the preexposure phase in Experiment 1. Subjects from the three preexposure groups were divided into two subgroups, one receiving a maximum shock duration of $2 \mathrm{sec}$ and the other a maximum of $6 \mathrm{sec}$. Shock intensity was $.5 \mathrm{~mA}$. A single barpress was required to terminate the shock. The average time between shocks, from shock offset to shock onset, was $20 \mathrm{sec}$, with a range from $12-30 \mathrm{sec}$. Three subjects were run simultaneously. The number of barpresses during preexposure and test was recorded.

\section{Results and Discussion}

Preexposure phase. The NCR and NP groups both showed a flat response rate over the three sessions, each averaging about four responses per session. The CR group responded in a similar manner during Sessions 1 and 2 but exhibited a large increase in responding in Session $3(M=14.18)$. The mean number of barpresses during preexposure over the three blocks of $1 \mathrm{~h}$ each was subject to a groups (3) $\times$ blocks (3) two-way ANOVA, with one factor repeated. The analysis indicated that the groups $[F(2,42)=27.82, \quad p<.001]$, blocks $[F(2,83)=$
75.43, $\mathrm{p}<.001 \mathrm{l}$, and groups $\times$ blocks interaction $[F(4,88)=89.55, p<.001]$ were significant. Subsequent Newman-Keuls multiple comparisons among the CR, NCR, and NP groups at each level of the three blocks revealed that $\mathrm{CR}$ subjects' responding increased from the second to the third block. CR subjects performed better than did NCR and NP groups only at the third block. There were no other reliable differences.

Test phase. The mean number of escape responses over the three blocks of 30 trials is shown in Figure 4. Since shock duration during test was not of interest in this study, a three-way ANOVA, groups (3) $\times$ shock duration $(2) \times$ blocks $(3)$, was performed to ascertain whether shock duration had an effect either by itself or interacting with the groups variable. No such effects were found. As a result, a groups (3) $\times$ blocks (3) two-way ANOVA, with one factor repeated, was performed on the pooled data from both shock durations. This analysis revealed a significant difference among groups $[F(2,44)=$ $33.64, \mathrm{p}<.001]$ and blocks $[\mathrm{F}(2,88)=187.66$, $\mathrm{p}<.001]$. The groups $\times$ blocks interaction was also significant $[\mathrm{F}(4,88)=13.11, \mathrm{p}<.001]$.

Newman-Keuls multiple comparisons for the CR, NCR, and NP groups at each level of blocks revealed that, while $C R$ subjects increased the number of escape responses from block to block, NP and NCR subjects showed a significant increment only from the second to the third block. Additional comparisons revealed that the CR and NCR groups differed reliably on blocks 2 and 3 , but not on block 1 . The NP group differed from the CR group only on the second block and from the NCR group on the second block.

The results reported above are similar to those of other studies that have used shock procedures during test, following preexposure to noncontingent appetitive reinforcement (e.g., White \& Katzev, 1977). Subjects exposed to contingent food escaped shocks

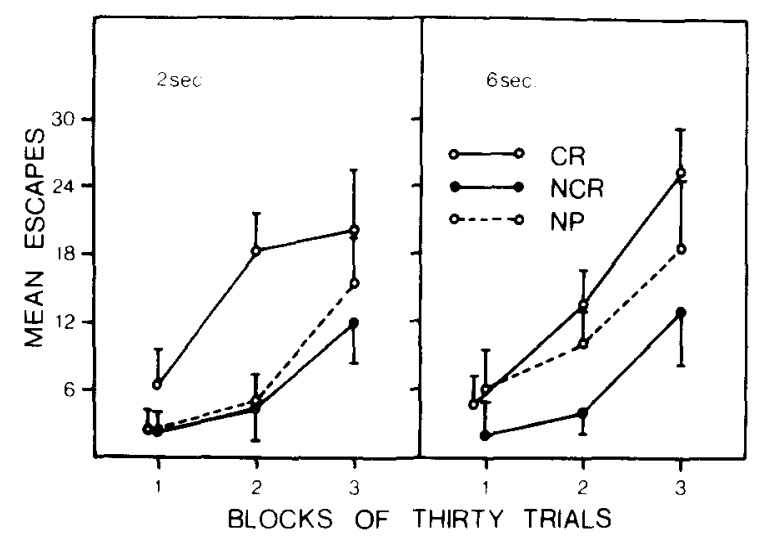

Figure 4. Mean ( \pm SD) number of escape responses during test over blocks of 30 trials as a function of food-contingent response (contingent:CR; noncontingent: NCR; and not preexposed: NP). 
more efficiently than did those that were exposed to noncontingent food.

Whereas in Experiment 1 the groups preexposed to escapable shock and to no shock performed in a similar manner during test, in Experiment 3 the contingent food group performed better than did the no food group. This latter finding can be attributed to a simple transfer of barpress responding acquired during the preexposure phase and/or to a transfer of learning about contingencies (learned competence; cf. Eisenberger, Leonard, Carlson, \& Park, 1979). Experiment 4 was designed, in part, to resolve the issue of simple transfer.

\section{EXPERIMENT 4}

In Experiment 3, the test phase differed from the preexposure phase in terms of US quality. However, during preexposure, the subjects with control had to press a bar in order to obtain food, while, in the test, they had to make the same response to escape shock. In the present experiment, different stimuli (food during preexposure and shock during test) and partially different response requirements (barpressing during preexposure and a running response plus barpressing during test) were employed.

The data obtained in Experiment 2 demonstrated that there was a generalization of learned helplessness, acquired by exposure to noncontingent shock, to an appetitive situation requiring a response different from that of the preexposure phase. The purpose of the present study was to determine whether the same resuits could be obtained by preexposing the mouse to noncontingent food and testing it with a shock-escape procedure.

\section{Method}

Subjects and Design. Twenty-four male BALB-c mice, 60-62 days of age at the start of the experiment, served as subjects. All other specifications were identical to those described in Experiment 1. There were three groups: One received food following a barpress response-Contingent Response (CR); one received yoked free food-noncontingent response (NCR); and one received no food-no preexposure to food (NP). Each replication consisted of six mice, two from each of the three experimental groups. The three-group design, with eight mice in each group, comprised the four replications.

Apparatus and Procedure. The preexposure phase was conducted in the same apparatus and in the same manner as described in Experiment 3. The test phase occurred $24 \mathrm{~h}$ after preexposure and was conducted in the straight alley used in Experiment 3. After being placed in the compartment, each subject received a .5-mA shock with a maximum duration of $30 \mathrm{sec}$. Shock could be terminated by escaping from the startbox, running down the alley, entering the goalbox, and then making a single barpress. The time between shock offset and onset of the next shock varied between 1 and $2 \mathrm{~min}$. The number of barpresses for food during preexposure and the number of trials in which mice escaped shock during test were recorded. Due to experimenter oversight, latencies were not recorded.

\section{Results and Discussion}

Preexposure phase. As in Experiment 3, the NCR and NP groups both showed a relatively low and flat response rate over the three sessions, with an overall mean of 3.67 barpresses per session. Group CR performed in a similar manner on block $1($ mean $=3.87)$ but increased its responding on blocks 2 and 3 (13.45 and 21.75 , respectively).

Mean numbers of barpresses for the three groups over the three 1-h daily sessions were subjected to a groups (3) $\times$ blocks (3) two-way ANOVA, with one factor repeated. The analysis indicated a significant difference for groups $[\mathrm{F}(2,21)=22.43, \mathrm{p}<.005]$, as well as for blocks $[F(2,42)=6.04, p<.05]$. The groups $\times$ blocks interaction was also significant $[F(4,42)=8.96, p<.01]$. Subsequent NewmanKeuls multiple comparisons revealed that, while the number of responses for NCR and NP subjects did not differ from block to block, CR subjects' responding increased from block to block. The differences between the CR and both the NCR and NP groups were significant for the second and third blocks.

Test phase. Figure 5 represents the mean number of barpresses to escape shock for each of the three groups for the three blocks of six trials. A groups (3) $\times$ blocks (3) two-way ANOVA, with one factor repeated, yielded a significant difference for groups $[F(1,21)=8.20, p<.01]$ and blocks $[F(2,42)=$ $64.54, \mathrm{p}<.001]$. The groups $\times$ blocks interaction was not significant $[\mathrm{F}(4,42)<1]$.

Newman-Keuls comparisons among the $C R$, NCR, and NP groups at each of the three blocks

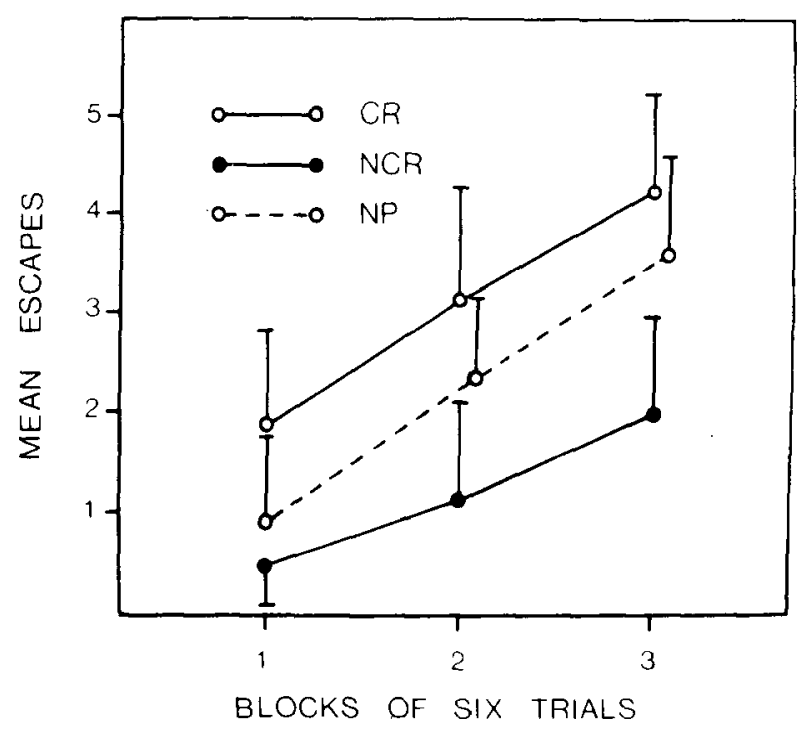

Figure 5. Mean ( \pm SD) number of escape responses during test over blocks of 30 trials as a function of food-contingent response (contingent: CR; noncontingent: NCR; and not preexposed: NP). 
indicated that CR and NP subjects' responding increased from block to block. These comparisons were not significant for NCR subjects. Additional comparisons revealed that, while the $C R$ group performed better than the NP group only on the first two blocks, the NP group differed reliably from the NCR group only on the last two blocks. The CR group performed significantly better than did the NCR group on all three blocks.

In summary, subjects that were exposed to an uncontrollable outcome (i.e., free food) showed poorer performance as compared with those that were exposed to "controllable" food or as compared with subjects that were not treated with either contingent or noncontingent food. These results replicate those of other experiments that used preexposure to noncontingent appetitive stimulus (Engberg et al., 1973; Goodkin, 1976; Welker, 1976; Wheatley et al., 1977). In those studies, preexposure to noncontingent food, as compared with preexposure to contingent food or no preexposure, interfered with the acquisition of a response that was different from the one used by the contingent group during preexposure. However, in those studies, stimulus quality was the same in preexposure and test, that is, food during both preexposure and test phases (Engberg et al., 1973; Welker, 1976; White \& Katzev, 1977) In the present experiment, not only were response requirements changed, but there was also a change in stimulus quality (as in Experiment 3): food during preexposure and shock during test. The results remain the same-noncontingent preexposure to food results in poor shock-escape performance.

In addition to the NCR group's performing more poorly than did the NP group, as in Experiment 3, there was evidence that the CR group performed better than did the NP group. It is unlikely that the relatively improved performance of the CR group was due to the simple transfer of barpress responding from the preexposure phase, since the test response involved running as well as barpress responding. This finding of enhanced performance by the CR group is similar to that reported by Goodkin (1976) for rats and by Caspy and Lubow (1981) for mice but is dissimilar to the results of Caspy et al. (1979) and to those of Experiment 1 in this study, both with mice.

\section{GENERAL DISCUSSION}

In the four experiments, it was demonstrated that subjects exhibited marked decrements in subsequent performance following preexposure to noncontingent stimuli. These results, of course, are similar to those of many other experiments within the learned helplessness framework (see Maier \& Seligman, 1976, for a review). The major findings in regard to the interference effect were: (1) A decrement in performance was evident when subjects preexposed to noncontingent stimuli were compared with those preexposed to a contingent stimulus or not preexposed at all. (2) The decremental effect following preexposure to noncontingent stimuli was apparent with three generalization procedures-(a) a change in stimuli, shock to food, from preexposure to test (Experiments 1 and 2); (b) a change in stimuli, food to shock, from preexposure to test (Experiments 3 and 4); and (c) a change in response requirements, barpressing during preexposure and alleyway running during test (Experiments 2 and 4). (3) A decrement in performance was evident when either uncontrollable short-duration shocks $(2 \mathrm{sec})$ or longduration shocks were used during preexposure (Experiments 1 and 2). (4) Retrace data indicated that subjects preexposed to noncontingent shock showed more activity in the test situation than did subjects exposed to contingent shock (Experiment 2).

As noted earlier, most of these data are in accord with those of previous studies that investigated the generalization effect of the preexposure to noncontingent stimuli (Altenor et al., 1975; Braud et al., 1969; Goodkin, 1976; Wheatley et al., 1977; White \& Katzev, 1977).

These experiments, together with the four reported in this paper, indicate quite clearly that there is a generalization of the interference effect that cuts across stimulus quality, response requirements, and situational factors. This very broad generalization is consistent with the learned helplessness explanation of the effects of uncontrollable aversive and appetitive stimuli. To the extent that the animal learns a general negative set, that there is no relationship between responding and outcome, then subsequent decremental effects should transfer to situations that are quite different from the preexposure situation. Thus, in the present experiment, we have demonstrated such generalized transfer, from appetitive preexposure to aversive test, from aversive preexposure to appetitive test, and from a barpress response to a running response. Likewise, of course, when the preexposure and test situations were the same, the interference effect was present. An examination of the size of the interference across the different situations indicated very little, if any, loss in interference with changes from preexposure to test situations.

While these data are congenial to learned helplessness theory, there are two pieces of data from these experiments that could provide difficulties for the Glazer and Weiss (1976a, 1976b) or Anisman et al. (1978) inactivity hypothesis as the basis for the interference effect: (1) that $2 \mathrm{sec}$ of uncontrollable shock produces as much interference on a subsequent test as $6 \mathrm{sec}$ of uncontrollable shock (Experiments 1 
and 2); and (2) that uncontrollable shock preexposure produces more activity in the test situation, as measured by the number of retraces, than does controllable shock. While these findings are not predictable from learned helplessness theory, they do not contradict it.

\section{REFERENCES}

Altenor, A., KAy, E., \& Richter, M. The generality of learned helplessness in the rat. Learning and Motivation, 1977, 8, 54-61.

Amsel, A., Rashotte, M. E., \& Mackinon, J. R. Partial reinforcement effects within subjects and between subjects. Psychological Monographs, 1966, 80(20, Whole No. 678).

Anisman, H., de Catanzaro, D., \& Remington, G. Escape performance following exposure to inescapable shock: Deficits in motor-response maintenance. Journal of Experimental Psychology: Animal Behavior Processes, 1978, 4, 197-218.

Braud, W., Wepmann, B., \& Russo, D. Task and species generality of the "helplessness" phenomenon. Psychonomic Science, 1969, 16, 154-155.

Caspy, T., Frommer, R., Weiner, I., \& Lubow, R. E. Generality of US preexposure effects: Effect of shock or food preexposure on water escape. Bulletin of the Psychonomic Society, 1979, 4, 15-18.

Caspy, T., \& Lubow, R. E. Performance decrement following US preexposure: The effect of number and duration of escapable and inescapable shock. Psychological Record, 1981, 31, 183-194.

Chen, J., \& Amsel, A. Prolonged, unsignaled, inescapable shocks increase persistence in subsequent appetitive instrumental learning. Animal Learning \& Behavior, 1977, 5, 377-385.

Eisenberger, R., Leonard, J. M., Carlson, J., \& Park, D. C. Transfer effects of contingent and noncontingent positive reinforcement: Mechanisms and generality. American Journal of Psychology, 1979, 92, 525-535.

Engberg, L. A., Hansen, G., Welker, R. L., \& Thomas, D. R. Acquisition of key-pecking via autoshaping as a function of prior experience: "Learned laziness"'? Science, 1973, 178, 1002-1004.

Glazer, H. I., \& WErss, J. M. Long-term and transitory interference effects. Journal of Experimental Psychology: Animal Behavior Processes, 1976, 2, 191-201. (a)
Glazer, H. I., \& Weiss, J. M. Long-term interference effect: An alternative to "learned helplessness." Journal of Experimental Psychology: Animal Behavior Processes, 1976, 2, 202-213. (b)

Goonkin, F. Rats learn the relationship between responding and environmental events: An expansion of the learned helplessness hypothesis. Learning and Motivation, 1976, 7, 382-393.

MaIen, S. F., \& JACKson, R. L. Learned helplessness: All of us were right (and wrong): Inescapable shock has multiple effects. In G. Bower (Ed.), The psychology of learning and motivation (Vol. 13). New York: Academic Press, 1979.

Maier, S. F., \& Seligman, M. E. P. Learned helplessness: Theory and evidence. Journal of Experimental Psychology: General, 1976, 105, 3-46.

Mullins, G. P., \& Winefield, A. H. Immunization and helplessness phenomena in the rat in a nonaversive situation. Animal Learning \& Behavior, 1977, 5, 281-284.

Overmier, J. B., \& Seligman, M. E. P. Effects of inescapable shock upon subsequent escape and avoidance learning. Journal of Comparative and Physiological Psychology, 1967, 63, 28-33.

Rosellini, R. A. Inescapable shock interferes with the acquisition of an appetitive operant. Animal Learning \& Behavior, 1978, 6, 155-159.

Seligman, M. E. P. Helplessness: On depression, development, and death. San Francisco: Freeman, 1975.

Seligman, M. E. P., \& Maier, S. F. Failure to escape traumatic shock. Journal of Experimental Psychology, 1967, 74, 1-9.

Seligman, M. E. P., Rosellini, R. A., \& Kozak, M. J. Learned helplessness in the rat: Time course, reversibility, and immunization. Journal of Comparative and Physiological Psychology, 1975, 88, 542-547.

WELKER, R. L. Acquisition of a free-operant-appetitive response in pigeons as a function of prior experience with responseindependent food. Learning and Motivation, 1976, 7, 394-405.

Wheatley, K. L., Welker, R. L., \& Miles, R. C. Acquisition of barpressing in rats following experience with responseindependent food. Animal Learning \& Behavior, 1977, 5, 236242.

White, M. T., \& Katzev, R. D. Noncontingent positive reinforcers retard later escape/avoidance learning in rats. Bulletin of the Psychonomic Society, 1977, 9, 319-321.

(Manuscript received December 19, 1980; revision accepted for publication May 20, 1981.) 